\title{
Remembering Yahya Ould Hamidoune
}

Toka Diagana

Yahya Ould Hamidoune, one of the most famous Mauritanian mathematicians, passed away in Paris, France, on March 11, 2011. Yahya was born in 1947 in Atar, Mauritania, to a family of very famous scholars and poets. After completing elementary and middle schools in Mauritania, Yahya attended high school and college in Cairo, Egypt, while his father was serving there as a diplomat. Next he went to France to pursue graduate studies. He received his Ph.D. degree in mathematics in 1978 from the University of Paris VI under the supervision of Michel Las Vergnas. He then joined the CNRS and was promoted to the rank of Research Fellow in 1981.

Yahya authored about one hundred papers, mainly on abstract theory of connectedness, enumerative combinatorics, the topology of Cayley graphs, Erdős-Heilbronn conjecture, Erdôs conjectures, subsequences of a zero-sum, the Diderrich conjecture, theorems of addition, the Waring problem over finite fields, and the problem of Frobenius. His most significant result is undoubtedly his proof of the Erdôs-Heilbronn conjecture, which he obtained in 1992 along with Dias da Silva. Additionally, he recently solved a question raised by Terence Tao. That new result is called Hamidoune's Freiman-Kneser theorem for nonabelian groups.

In 2001 Yahya was awarded the Prix Chinguitt for his work "Recent results in additive number theory". The Prix Chinguitt is the most important prize that the Mauritanian government awards yearly to recognize the merits of either a citizen of Mauritania or of another country for major research achievements.

Apart from his research activities, Yahya had various ambitions for Mauritania, which he so loved. Among other things, he particularly wanted

Toka Diagana is professor of mathematics at Howard University. His email address is tdiagana@howard.edu.

DOI: http://dx.doi.org/10.1090/noti859 to see his country emerge among the nations in which scientific research is an essential tradition. Such an ambition led him in 2002 to organize a large meeting in Nouakchott, Mauritania, which attracted nearly all the Mauritanian scientists from around the world. The meeting was, without any doubt, a great success. Unfortunately, a repeat of that meeting has not yet occurred, mostly due to the political instability into which Mauritania has fallen in recent years.

Despite his busy schedule, Yahya was a tireless advocate when it came to assisting in the improvement of education in Mauritania. In particular, he was involved in numerous worthwhile projects. For instance, a few years ago he worked tirelessly with Mohameden Ould Ahmedou (Giessen University, Germany) on a project that consisted of founding preparatory classes for the Grandes Écoles of Engineering. More recently, Yahya, along with Mohameden Ould Ahmedou and Alain Plagne (École Polytechnique, France), had undertaken another major project related to education in Mauritania. Their project was to provide opportunities for bright young students from Mauritania to pursue their studies at the École Polytechnique of Paris. Yahya was deeply committed to this project, but unfortunately, it will now be done without him. Clearly, Mauritania has lost one of its best ambassadors in the person of Yahya Ould Hamidoune.

Acknowledgment: The author expresses his thanks to Profs. Mohameden Ould Ahmedou, Ahmedou Ould Haouba, Saleh Ould Moulaye Ahmed, and Alain Plagne for careful reading of this note and insightful comments. 